\title{
Impact of the COVID-19 pandemic on hospital admissions for cardiovascular diseases in a large Brazilian urban center
}

\author{
Edmar Geraldo Ribeiro [1], Pedro Cisalpino Pinheiro ${ }^{[2],}$ Bruno Ramos Nascimento ${ }^{[2]}$, \\ João Pedro Pereira Cacique ${ }^{[1]}$, Renato Azeredo Teixeira ${ }^{[2]}$, Jamil de Souza Nascimento ${ }^{[3]}$, \\ Tulio Batista Franco ${ }^{[4]}$, Luisa Campos Caldeira Brant ${ }^{[2]}$ and Deborah Carvalho Malta ${ }^{[1]}$
}

\author{
[1]. Universidade Federal de Minas Gerais, Escola de Enfermagem, Departamento Materno Infantil, Belo Horizonte, MG, Brasil. \\ [2]. Universidade Federal de Minas Gerais, Faculdade de Medicina, Belo Horizonte, MG, Brasil. \\ [3]. Ministério da Saúde, Superintendência Estadual do Ministério da Saúde em Minas Gerais. Belo Horizonte, MG, Brasil. \\ [4]. Universidade Federal Fluminense, Departamento de Planejamento em Saúde, Rio de Janeiro, RJ, Brasil.
}

\begin{abstract}
Introduction: The COVID-19 pandemic has had a great impact on the behavior of individuals and the organization of health systems. This study analyzed the COVID-19 pandemic's effect on public hospitalizations for cardiovascular diseases (CVD) in a large city in Brazil, Belo Horizonte, MG, with approximately 2.5 million inhabitants. Methods: In a time-series analysis, this study used administrative data from the national "Hospital Information System" from 2010 to February 2020 to estimate the expected number of hospitalizations for CVD by month during the COVID-19 pandemic in Belo Horizonte in 2020 using the Auto-Regressive Integrated Moving Average model. For CVD, this study compared the expected number of hospital admissions, intensive care use, deaths during hospitalization, and mean length of stay with the observed number during the period. Results: There were 6,517 hospitalizations for CVD from March to December 2020, a decrease of 16.3\% (95\% CI: 4.7-25.3) compared to the projected. The number of intensive care hospitalizations for CVD fell $24.1 \%$ (95\% CI 13-32.7). The number of deaths also decreased (17.4\% [ $80 \%$ CI: 0 - 0.30]), along with the reduction in hospitalizations, as did the length of stay for CVD hospitalizations. These reductions, however, were not significant. Conclusions: Hospitalizations for CVD were 16.3\% lower than expected in a large Brazilian city, possibly due to the fear of getting infected or going to hospitals. Public campaigns informing how to proceed in case of CVD show that prompt urgent attention is essential to mitigate the indirect effects of the pandemic on CVD.
\end{abstract}

Keywords: Cardiovascular diseases. Hospitalization. COVID-19. Time series studies. Health systems. Epidemiology.

\section{INTRODUCTION}

Cardiovascular diseases (CVD) are the leading causes of death worldwide and are responsible for the loss of 17.9 million lives each year, of which one third occur prematurely in people under the age of $70^{1}$. According to the Brazilian Unified Health System (Sistema Único de Saúde, SUS, in Portuguese) databases, CVDs are also responsible for considerable morbidity. In addition to being the cause of most disability pensions, they are also associated with high rates of hospitalization and a progressive increase in hospital costs, most likely due to the increased complexity of treatments ${ }^{2,3}$. According to data from the Hospital Information System (Sistema

\footnotetext{
Corresponding author: Edmar Geraldo Ribeiro.

e-mail: edmargribeiro@gmail.com

(D) https://orcid.org/0000-0002-7201-9566_

Received 29 April 2021

Accepted 23 July 2021
}

de Informação Hospitalar, SIH-DATASUS, in Portuguese), CVDs that resulted in the highest number of hospitalizations in Brazil in the past 10 years were, in this order: heart failure (HF), stroke, and Acute Coronary Syndromes (ACS) ${ }^{4}$.

In 2020, with the coronavirus pandemic (COVID-19), social distancing policies were adopted worldwide, and health systems were reorganized to deal with the increasing number of patients infected with Coronavirus 2 Severe Acute Respiratory Syndrome $(\mathrm{SARS}-\mathrm{CoV}-2)^{5}$, prioritizing such services. During the same period, studies in high- and low-income countries showed changes in the pattern of hospital admissions with an unexpected decline in admissions for $\mathrm{CVD}^{6,7,8}$. Studies in the city of São Paulo and in Brazil for the first five months of the pandemic also showed a decline in hospital admissions ${ }^{6,7}$. Given the known deleterious effects of COVID-19 on the cardiovascular system, it is important to analyze whether these unexpected declines occurred in other locations, as we would expect an opposite trend, since SARS-CoV-2 leads to an 
inflammatory response and predisposes the patient to thrombotic events, which could ultimately result in a greater demand for hospitalization due to $\mathrm{CVD}^{9}$.

The present study aims to analyze the impact of the COVID-19 pandemic on hospital admissions for CVD in a large city from a middle-income country (Belo Horizonte, Minas Gerais, Southeast Brazil) in 2020.

\section{METHODS}

This is a time-series study, using data from SIH-DATASUS ${ }^{4}$ for hospitalizations in Belo Horizonte - a large urban center in Brazil, with approximately 2.5 million inhabitants - due to the following causes: HF, considering hospitalizations with a main diagnosis of I50, according to the $10^{\text {th }}$ revision of the International Classification of Diseases (ICD-10) codes; stroke, based on hospitalizations with codes I60 - I64; ACS, codes I20 - I24; and CVD, which includes the 3 previous groups. The following stratified variables were analyzed for each cause: number of hospitalizations, number of hospitalizations with Intensive Care Unit (ICU) admissions, number of hospitalizations resulting in death, and average length of hospital stay. In addition, analyses were stratified by age, considering the 60 years of age cutoff (adults and older adults), and by sex. Data were analyzed until December 2020.

The Auto-Regressive Integrated Moving Average (ARIMA) for a time-series model was used to estimate the expected number of the variables of interest within the period, from March to December 2020, which serves as a hypothetical scenario for comparison with data observed during the same period. ARIMA is a combination of an autoregressive model with differentiation and a moving average model ${ }^{10}$. For the projection of the indicators in the study period, a monthly time series was built for the variables of interest from January 2010 to December 2020. However, for a better understanding and visualization, the results from January 2015 to December 2020 were presented. February 2020 was defined as the last month in which the trends for study variables would not have been influenced by the COVID-19 pandemic, considering that the Belo Horizonte City Hall (Prefeitura de Belo Horizonte, $\mathrm{PBH}$, in Portuguese) issued social isolation policies, closing schools and other non-essential services, in March $2020^{11}$. The months from March to December 2020 were not considered in the model estimates, because changes observed during this period would affect the estimated model and, consequently, the projections. All statistical analyses were performed, using R (R Core Team, 2020) ${ }^{12}$, together with the fpp2 package ${ }^{13}$. In the supplementary section, we present a table with the final estimated model for each variable and subgroup (Table 01). Autocorrelation Function (ACF) and Partial Autocorrelation Function (PACF) figures for each model are also available in the supplementary section. More details on how the time-series was modeled can be found on the package website (https://otexts.com/fpp2/arima-r.html).

Once models and projections for each of the analyzed series were estimated, expected and observed indicators were compared. For the total number of hospitalizations, ICU admissions, and deaths, this study compared the observed sum between March and December, with the same sum based on the projection of the time series for 2020. For the average number of hospital days, the average of the period observed was compared with the average of the projected period. Calculations were performed considering a percent variation, that is, the ratio between observed and projected, subtracted by 1 . To incorporate the uncertainty of the projection in the analysis, the upper and lower limits of the projection's prediction intervals ( $80 \%$ and $95 \%$ ) were also used for comparisons between scenarios.

The SIH-DATASUS information was obtained in an aggregated form, without patient identification, so there was no need for submission to an Institutional Review Board (IRB). The study was conducted in accordance with Resolution No. 510 of April 7, 2016 of the National Health Council (Conselho Nacional de Saúde, CNS, in Portuguese).

\section{RESULTS}

Figure 1 shows the time-series, from January 2015 to December 2020 , with the number of observed and expected hospitalizations, as well as the $80 \%$ and $95 \%$ prediction intervals, for: CVD, stroke, HF, and ACS, for both sexes and all ages. There was a significant reduction in the number of hospitalizations for CVD. CVD hospitalizations were reduced in $16.3 \%$ in the pandemic period of 2020, compared to what was expected for the period. The series of hospitalizations due to ACS (Figure 1), which had less variability in the period between January 2015 and February 2020, depicts the difference between the observed and expected scenarios. For example, the average projection scenario estimates 3,013 hospitalizations for ACS in the 2020 pandemic period, while only 2,369 admissions due to this cause actually occurred.

Figure 2 shows the time-series with the number of observed and expected ICU admissions, with prediction intervals, for CVD, stroke, HF, and ACS. Similar to the total number of hospitalizations, those with ICU stay showed a significant and continuous drop after February 2020. Interestingly, there was an increase in the number of ICU admissions between 2015 and the beginning of 2020, for all outcomes, markedly for total CVD. In the months following February, the upward trend reversed. Considering total CVDs, hospitalizations with ICU stay fell $24.1 \%$ (95\% CI: 13-32.7) during the 2020 pandemic period.

Figure 3 presents the comparison between the observed and expected scenarios for all outcomes and analyzed variables. Considering CVD, the variation indicates that the observed variables showed a proportional decrease, except for the average length of hospital stay. The most expressive reductions were observed for the number of hospitalizations and the total number of those requiring ICU admissions. For the number of in-hospital deaths, the reduction was only significant for the $80 \%$ prediction interval (17.4\% [ $80 \%$ CI: $0 \%-0.30 \%]$ ). For ACS, the trends were similar, while for HF and stroke, the variation was not significant for the analyzed variables, except for the number of ICU hospitalizations, since HF was significantly lower than expected.

Table 1 shows the proportional variation between observed and expected scenarios, for CVD, stroke, HF, and ACS, stratified by sex and age (cutoff of 60 years of age). The values indicate the variation 


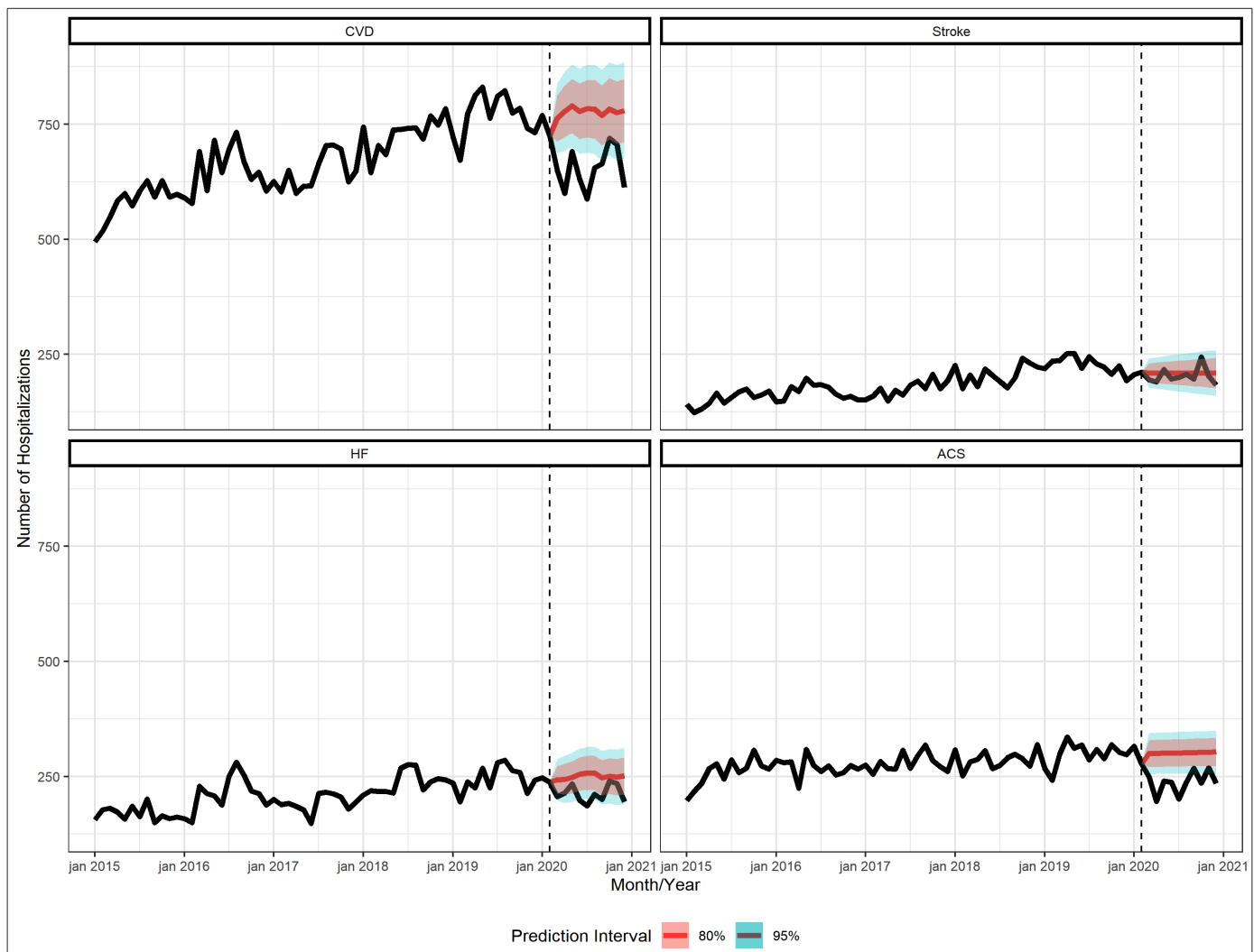

FIGURE 1: Time-series, from January 2015 to December 2020, with the number of observed and expected hospitalizations, and the $80 \%$ and $95 \%$ prediction intervals.

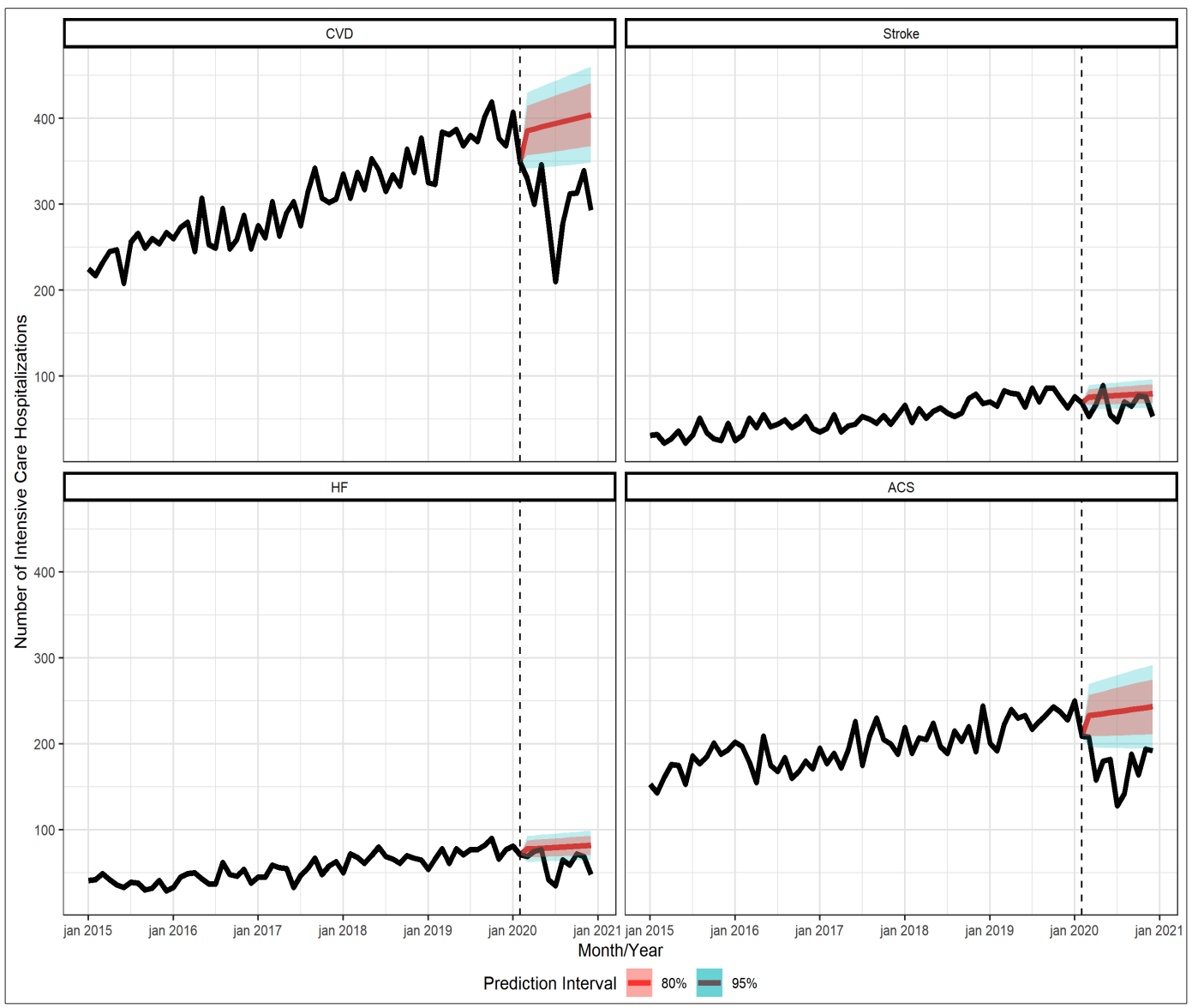

FIGURE 2: Time-series, from January 2015 to December 2020, with the number of observed and expected hospitalizations with ICU admissions, and the $80 \%$ and $95 \%$ prediction intervals. 
Ribeiro EG et al. - Cardiovascular hospitalizations in the pandemic

TABLE 1: Percentage variation between observed and projected (ARIMA) Hospitalizations, CVD, Stroke, HF, ACS, March - December 2020.

\begin{tabular}{|c|c|c|c|c|c|c|c|c|c|}
\hline & \multicolumn{3}{|c|}{ Both Sexes } & \multicolumn{3}{|c|}{ Female } & \multicolumn{3}{|c|}{ Male } \\
\hline & Obs & Exp & $\%$ Variation & Obs. & Fore. & $\%$ Variation & Obs. & Fore. & $\%$ Variation \\
\hline \multicolumn{10}{|c|}{ Number of Hospitalizations } \\
\hline $\begin{array}{c}\text { CVD } \\
\text { All ages }\end{array}$ & 6517 & 7782.8 & $\begin{array}{c}-16.3 \\
(-4.7 ;-25.3)^{*}\end{array}$ & 2980 & 3606.6 & $\begin{array}{c}-17.4 \\
(-3.3 ;-27.9)^{*}\end{array}$ & 3537 & 4262.5 & $\begin{array}{c}-17 \\
(-4.8 ;-26.5)^{*}\end{array}$ \\
\hline $\begin{array}{l}\text { CVD } \\
0-59 y\end{array}$ & 2118 & 2482.1 & $\begin{array}{c}-14.7 \\
(1.1 ;-26.2)\end{array}$ & 825 & 1081.2 & $\begin{array}{c}-23.7 \\
(-5.3 ;-36.1)^{*}\end{array}$ & 1293 & 1425.8 & $\begin{array}{c}-9.3 \\
(13.2 ;-24.4)\end{array}$ \\
\hline $\begin{array}{l}\text { CVD } \\
60+y\end{array}$ & 4399 & 5363.2 & $\begin{array}{c}-18 \\
(-5.8 ;-27.4)^{\star}\end{array}$ & 2155 & 2592.2 & $\begin{array}{c}-16.9 \\
(-1.1 ;-28.3)^{*}\end{array}$ & 2244 & 2783.1 & $\begin{array}{c}-19.4 \\
(-5.5 ;-29.7)^{*}\end{array}$ \\
\hline $\begin{array}{l}\text { Stroke } \\
\text { All ages }\end{array}$ & 2029 & 2095.7 & $\begin{array}{c}-3.2 \\
(20.4 ;-19.1)\end{array}$ & 985 & 1139.1 & $\begin{array}{c}-13.5 \\
(6.2 ;-27.1)\end{array}$ & 1044 & 1038.6 & $\begin{array}{c}0.5 \\
(34 ;-19.6)\end{array}$ \\
\hline Stroke $0-59$ & 625 & 757.1 & $\begin{array}{c}-17.5 \\
(8.1 ;-33.2)\end{array}$ & 281 & 386.1 & $\begin{array}{c}-27.2 \\
(4.1 ;-44.1)\end{array}$ & 344 & 348.6 & $\begin{array}{c}-1.3 \\
(55.3 ;-27.7)\end{array}$ \\
\hline Stroke $-60+$ & 1404 & 1390.2 & $1(30 ;-17.4)$ & 704 & 735.0 & $\begin{array}{c}-4.2 \\
(25.6 ;-22.6)\end{array}$ & 700 & 763.7 & $\begin{array}{c}-8.3 \\
(20.8 ;-26.2)\end{array}$ \\
\hline $\begin{array}{c}\mathrm{HF} \\
\text { All ages }\end{array}$ & 2119 & 2501.5 & $\begin{array}{c}-15.3 \\
(9 ;-30.7)\end{array}$ & 1080 & 1284.6 & $\begin{array}{c}-15.9 \\
(17.2 ;-34.4)\end{array}$ & 1039 & 1170.9 & $\begin{array}{c}-11.3 \\
(19.4 ;-29.4)\end{array}$ \\
\hline $\mathrm{HF}-0-59$ & 515 & 657.1 & $\begin{array}{c}-21.6 \\
(9 ;-38.8)\end{array}$ & 198 & 315.2 & $\begin{array}{c}-37.2 \\
(-6.2 ;-52.8)^{*}\end{array}$ & 317 & 347.2 & $\begin{array}{c}-8.7 \\
(44.6 ;-33.3)\end{array}$ \\
\hline HF - 60+ & 1604 & 1880.1 & $\begin{array}{c}-14.7 \\
(11.3 ;-30.8)\end{array}$ & 882 & 961.5 & $\begin{array}{c}-8.3 \\
(37.1 ;-31.1)\end{array}$ & 722 & 855.5 & $\begin{array}{c}-15.6 \\
(14.5 ;-33.2)\end{array}$ \\
\hline $\begin{array}{c}\text { ACS } \\
\text { All ages }\end{array}$ & 2369 & 3013.9 & $\begin{array}{c}-21.4 \\
(-7.5 ;-31.7)^{\star}\end{array}$ & 915 & 1168.0 & $\begin{array}{c}-21.7 \\
(3.2 ;-36.9)\end{array}$ & 1454 & 1832.8 & $\begin{array}{c}-20.7 \\
(-2.7 ;-33)^{\star}\end{array}$ \\
\hline ACS - 0-59 & 978 & 1116.3 & $\begin{array}{c}-12.4 \\
(14.7 ;-29.1)\end{array}$ & 346 & 378.8 & $\begin{array}{c}-8.7 \\
(42.1 ;-32.7)\end{array}$ & 632 & 753.1 & $\begin{array}{c}-16.1 \\
(14.7 ;-33.8)\end{array}$ \\
\hline ACS - 60+ & 1391 & 1927.6 & $\begin{array}{c}-27.8 \\
(-12.4 ;-38.7)^{*} \\
\end{array}$ & 569 & 796.8 & $\begin{array}{c}-28.6 \\
(-5.2 ;-42.7)^{*}\end{array}$ & 822 & 1133.2 & $\begin{array}{c}-27.5 \\
(-8.9 ;-39.7)^{*}\end{array}$ \\
\hline \multicolumn{10}{|c|}{ Number of ICU Hospitalizations } \\
\hline $\begin{array}{c}\text { CVD } \\
\text { All ages }\end{array}$ & 2999 & 3951.3 & $\begin{array}{c}-24.1 \\
(-13 ;-32.7)^{*}\end{array}$ & 1288 & 1677.5 & $\begin{array}{c}-23.2 \\
(-8 ;-34.1)^{*}\end{array}$ & 1711 & 2294.5 & $\begin{array}{c}-25.4 \\
(-12 ;-35.3)^{*}\end{array}$ \\
\hline CVD - 0-59 & 1115 & 1381.2 & $\begin{array}{c}-19.3 \\
(2 ;-33.2)\end{array}$ & 424 & 535.1 & $\begin{array}{c}-20.8 \\
(10.3 ;-38.2)\end{array}$ & 691 & 841.5 & $\begin{array}{c}-17.9 \\
(7.5 ;-33.6)\end{array}$ \\
\hline CVD - 60+ & 1884 & 2654.0 & $\begin{array}{c}-29 \\
(-20.2 ;-36.1)^{*}\end{array}$ & 864 & 1141.5 & $\begin{array}{c}-24.3 \\
(-7.7 ;-35.8)^{*}\end{array}$ & 1020 & 1445.9 & $\begin{array}{c}-29.5 \\
(-15.7 ;-39.4)^{\star}\end{array}$ \\
\hline $\begin{array}{c}\text { Stroke } \\
\text { All ages }\end{array}$ & 652 & 776.8 & $\begin{array}{c}-16.1 \\
(4.8 ;-30)\end{array}$ & 322 & 390.8 & $\begin{array}{c}-17.6 \\
(12.9 ;-35.2)\end{array}$ & 330 & 416.6 & $\begin{array}{c}-20.8 \\
(5 ;-36.4)\end{array}$ \\
\hline $\begin{array}{c}\text { Stroke - } \\
0-59\end{array}$ & 242 & 312.0 & $\begin{array}{c}-22.4 \\
(14.8 ;-41.4)\end{array}$ & 114 & 156.6 & $\begin{array}{c}-27.2 \\
(42.7 ;-51.1)\end{array}$ & 128 & 155.1 & $\begin{array}{c}-17.5 \\
(40.2 ;-41.5)\end{array}$ \\
\hline Stroke $-60+$ & 410 & 455.7 & $\begin{array}{c}-10 \\
(20.9 ;-28.3)\end{array}$ & 208 & 234.4 & $\begin{array}{c}-11.3 \\
(30.2 ;-32.7)\end{array}$ & 202 & 233.3 & $\begin{array}{c}-13.4 \\
(29.1 ;-34.9)\end{array}$ \\
\hline $\begin{array}{c}\mathrm{HF} \\
\text { All ages }\end{array}$ & 611 & 796.2 & $\begin{array}{c}-23.3 \\
(-3.7 ;-36.2)^{*}\end{array}$ & 303 & 407.5 & $\begin{array}{c}-25.6 \\
(0.1 ;-40.8)\end{array}$ & 308 & 396.3 & $\begin{array}{c}-22.3 \\
(5.5 ;-38.5)\end{array}$ \\
\hline HF - 0-59 & 150 & 210.7 & $\begin{array}{c}-28.8 \\
(11 ;-47.6)\end{array}$ & 56 & 91.0 & $\begin{array}{c}-38.5 \\
(22.4 ;-58.9)\end{array}$ & 94 & 115.0 & $\begin{array}{c}-18.3 \\
(53 ;-44.3)\end{array}$ \\
\hline HF - 60+ & 461 & 592.8 & $\begin{array}{c}-22.2 \\
(-1.7 ;-35.7)^{\star}\end{array}$ & 247 & 304.7 & $\begin{array}{c}-18.9 \\
(16.5 ;-37.8)\end{array}$ & 214 & 279.3 & $\begin{array}{c}-23.4 \\
(5.5 ;-39.9)\end{array}$ \\
\hline $\begin{array}{c}\text { ACS } \\
\text { All ages }\end{array}$ & 1736 & 2379.4 & $\begin{array}{c}-27 \\
(-10.9 ;-38.2)^{\star}\end{array}$ & 663 & 889.8 & $\begin{array}{c}-25.5 \\
(-0.5 ;-40.4)^{*}\end{array}$ & 1073 & 1502.6 & $\begin{array}{c}-28.6 \\
(-10.5 ;-40.6)^{*}\end{array}$ \\
\hline ACS - 0-59 & 723 & 834.0 & $\begin{array}{c}-13.3 \\
(22.1 ;-32.8)\end{array}$ & 254 & 280.1 & $\begin{array}{c}-9.3 \\
(53.9 ;-35.7)\end{array}$ & 469 & 557.4 & $\begin{array}{c}-15.9 \\
(24.2 ;-36.4)\end{array}$ \\
\hline ACS - 60+ & 1013 & 1531.9 & $\begin{array}{c}-33.9 \\
(-18.7 ;-44.3)^{\star}\end{array}$ & 409 & 601.8 & $\begin{array}{c}-32 \\
(-6.9 ;-46.5)^{*}\end{array}$ & 604 & 923.7 & $\begin{array}{c}-34.6 \\
(-15.8 ;-46.5)^{*}\end{array}$ \\
\hline
\end{tabular}

*Negative variation even considering the lower bond of the prediction interval.

In parentheses percent variation estimated using, respectively, upper and lower of the 95\% prediction Interval. 


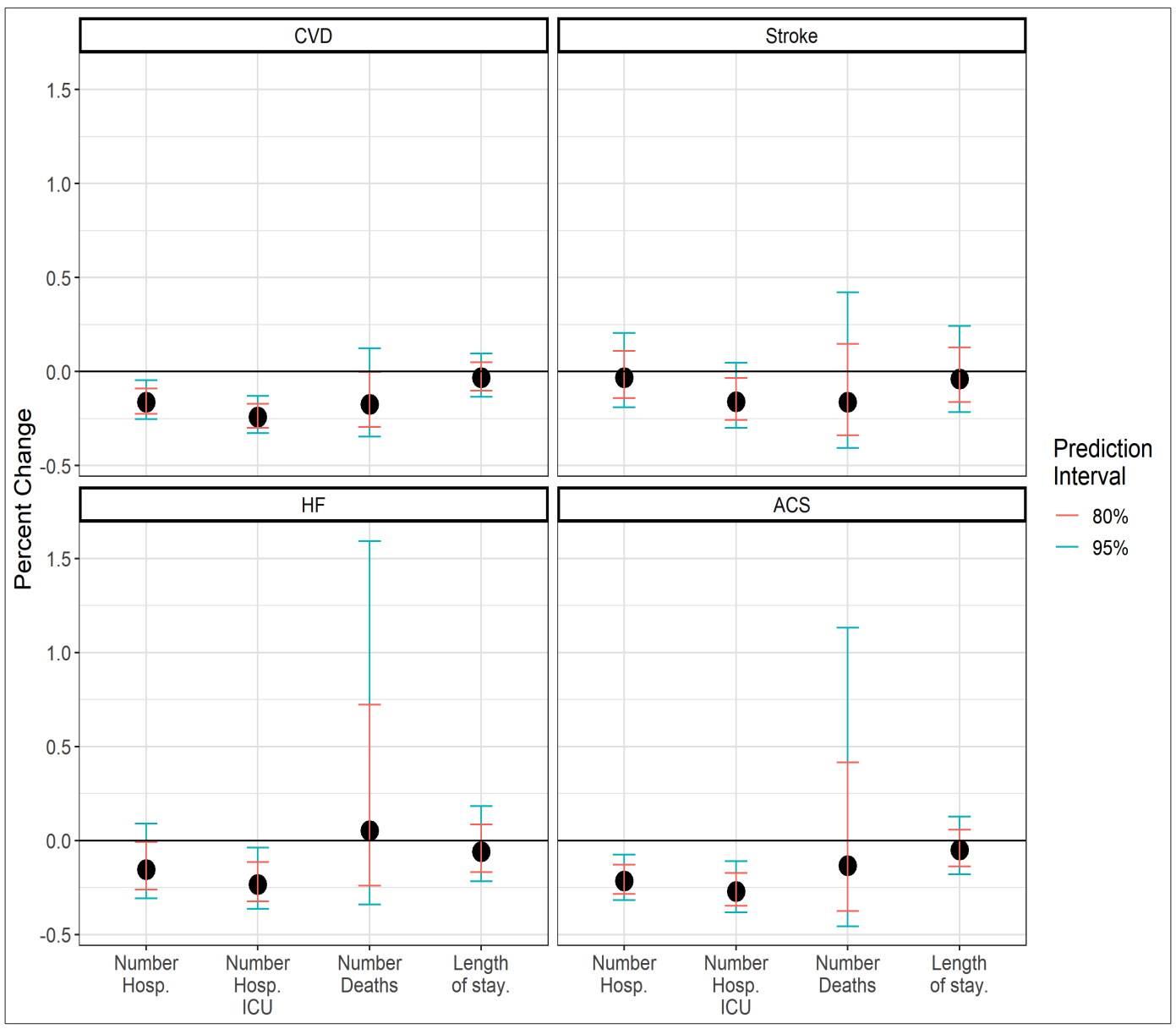

FIGURE 3: Comparison between the observed and expected scenarios for all outcomes and analyzed variables: number of hospitalizations, number of hospitalizations with ICU admission, in-hospital deaths, and length of hospital stay.

based on the average projection scenario and variation is presented in the parentheses, considering the upper and lower limits (95\%) of the prediction interval, respectively. Considering the number of hospitalizations for CVD, a significant decline was observed for all subgroups, except for men under 60 years of age, as well as a decrease in hospitalizations for ACS in older adults for both sexes. Regarding ICU admissions, it is worth noting that the reduction was significant for CVD, HF, and ACS only for older adults.

When the number of hospitalizations resulting in death and the average number of hospital days were analyzed, no significant difference was found for any of the subgroups (data not shown).

\section{DISCUSSION}

During the COVID-19 pandemic in 2020, a decline in the number of hospital admissions and in the number of individuals admitted to ICU beds for total CVD and for ACS was identified in Belo Horizonte, when compared to the historical series since 2015. For total CVD, this decline occurred for both sexes in older adults, and for women when considering younger adults $(<60 \mathrm{y})$ and number of hospitalizations. For hospitalizations due to ACS, the reduction was significant only for individuals over 60 years of age, suggesting that the impact on ICU admissions for CVD was differential according to the age group, revealing more unfavorable trends for older adults. Regarding hospitalizations resulting in death, although we observed a reduction in the number of hospital admissions, there was a non-significant absolute reduction for inhospital deaths, in parallel with the reduction in hospitalizations, possibly due to a greater severity of hospitalized individuals ${ }^{6}$. As for the average length of hospital stay, no significant difference was found when compared to the historical series. We hypothesized that this resulted from two opposing trends: reducing hospital days as much as possible due to the risk of exposure to COVID-19 and increasing hospital stay due to greater severity of hospitalized patients. Taken together, our data reveal a major impact of the COVID-19 pandemic on hospital admissions for CVD, showing that the effects of the pandemic are beyond those directly caused by viral infection.

The reduction in hospitalizations for CVD has also been described in other countries, such as Italy, Spain, Austria, the United States, and China ${ }^{5,8,14,15,16}$. In Northern Italy, the number of hospitalizations for ACS decreased 28\% between February 20 and March 31, 20205. In California (US), the weekly hospitalization rate for acute myocardial infarction also decreased from March 4 to April 14 by up to $48 \%{ }^{17}$. In China, stroke admissions decreased by $40 \%$ in February 2020 as compared to 2019 . The rate of fibrinolysis and thrombectomy procedures also decreased, but to a lesser extent $(25 \%)^{18}$. During this period, authors reported a decline in hospital capacity dedicated to stroke treatment of $50 \%$ 
in most institutions ${ }^{19}$. In addition to the reorganization of health systems - with the deactivation of services to meet urgent needs or to increase intensive capacity for patients infected with SARSCOV2, the delimitation of specific hospitals for COVID-19, and the implementation of alternative therapeutic pathways ${ }^{20}$ - there are also other explanations for the phenomenon of reduction of hospitalizations for CVD observed in several countries. Due to social distancing regulations and to the fear of contracting COVID-19, individuals sought out health care less frequently, especially those with CVD or risk factors, as they were part of the high-risk population for mortality ${ }^{21,22}$. In addition, isolation may make it difficult for others to detect cardiovascular symptoms, and therefore not transport patients to a hospital in a timely manner ${ }^{23}$.

It is important to highlight that, in parallel with the reduction in hospitalizations due to CVD during the pandemic, an excess mortality was also observed due to natural causes in several locations $\mathrm{s}^{24,25}$. Excess mortality measures the number of deaths that exceeds those expected for a given period based on the historical series, thus reflecting direct and indirect effects of the pandemic on the mortality of a given population ${ }^{26}$. Studies suggest that SARSCOV2 infection alone may not explain all beyond-expected deaths that occurred during the pandemic ${ }^{27}$. Analyzing causes of deaths that occurred during the pandemic in the US from March 1 to April 25 , only $65 \%$ were directly attributed to COVID-19, while the other main causes were: diabetes, Alzheimer's disease, and CVD ${ }^{28}$. In addition, in Italy, there was a 58\% increase in out-of-hospital sudden deaths between February 21 and March 31, 2020, compared to 2019, suggesting that more deaths from CVD may have occurred before individuals were admitted to hospitals ${ }^{29}$.

A recent study evaluating the excess of cardiovascular mortality during the COVID-19 pandemic in six Brazilian capitals found that CVD mortality increased in most cities, markedly in Northern capitals $^{30}$. However, in more developed cities, there was a reduction in ACS and stroke deaths, and the excess of CVD deaths occurred only due to the increase in unspecified cardiovascular events ${ }^{30}$. It is important to emphasize that this increase in unspecified cardiovascular deaths correlated with the increment in home deaths, suggesting that CVD deaths may have occurred without health care, and therefore lack a definitive diagnosi ${ }^{30}$. In addition, Brant et al. showed that excess CVD mortality was higher in less developed cities, which may be related to the transport infrastructure, difficulties to access healthcare services, or a collapse in the health system $^{30}$.

In the context of the aforementioned data, the present study suggests that the reduction in hospitalizations for CVD may be an indirect effect of the pandemic. The hypothesis is that individuals sought out less hospital care for acute or chronic decompensated CVD, but this did not result in a reduction in CVD in-hospital mortality. In fact, there may have been an increase in the number of CVD overall deaths, but without a definite diagnosis due to a lack of medical care. It is worth noting that the indirect effects of the pandemic on CVDs may last for years, due to the postponement or interruption of primary and secondary preventive measures for CVD during the pandemic, and the increase in cardiovascular risk factors during this period (such as physical inactivity and the consumption of alcohol, tobacco, and processed foods), which have long-term effects on $\mathrm{CVD}^{22,31,32}$. A virtual study conducted by the Pan American Health Organization (PAHO), carried out in 158 countries, showed that preventive services and treatment of chronic non-communicable diseases (NCDs) were seriously affected, posing a threat to the population with $\mathrm{CVD}^{33}$. Furthermore, another study revealed that the volume of diagnostic procedures for CVD decreased by $42 \%$ from March 2019 to March 2020, and 64\% from March 2019 to April 2020 in 108 countries, and these procedures are key to effective treatment guidance. This issue worsens the impacts on the care of patients with cardiovascular risks ${ }^{34}$.

\section{LIMITATIONS}

The present study has limitations. As a retrospective observational study, with data derived from a national database (HIS-DATASUS) ${ }^{4}$, it is possible that there was underreporting, notification delays, or erroneous data entry. However, analyzing the historical series, data about hospitalizations in a certain month are, mostly (average $98.3 \%$ ) processed within four months. In 2018 and 2019 , on average, only $1.7 \%$ of admissions were processed after the fourth month (not counting the month of interest), reinforcing our findings. In 2020, the processing period followed the same path. We used data processed until April 2021, which minimizes the possibility of underreporting in the analysis period. In addition, this is a single-city study of public hospitalizations, and it is well-known that the impact of the pandemic is heterogeneous between locations, which hinders the generalization of our data to other Brazilian municipalities. However, data from other regions of the world have already depicted similar trends, supporting our findings.

The impact of the COVID-19 pandemic resulted in changes in the scenario of hospitalizations due to CVD, with a decrease in the use of healthcare services. Public awareness efforts about acute cardiovascular symptoms requiring immediate hospital care, even during social isolation, as well as informative campaigns about the reorganization of healthcare services, must be carried out and encouraged. In addition, the resumption of health promotion and preventive measures for CVDs must adapt to the new reality and be implemented as soon as possible so as to manage the increased cardiovascular risk of individuals during the pandemic, in an attempt to minimize its deleterious effects on cardiovascular health.

\section{CONCLUSION}

During the first months of the COVID-19 pandemic, a reduction in the number of CVD admissions was observed in Belo Horizonte, as compared to the historical series since 2015. This reduction in the total number of hospitalizations and those requiring ICU stay for CVD may have presumably occurred due to social isolation, reduced access to healthcare services, fear of contamination, among others. Failure to seek out health care raises concerns about the clinical evolution and prognosis of patients with CVD during pandemic times. Public awareness campaigns about the importance of seeking medical care in case of acute cardiovascular symptoms, explanation about new healthcare flows, in addition to the resumption of measures for health promotion and cardiovascular risk factor controls, should be prioritized. 


\section{ACKNOWLEDGMENTS}

We offer our deepest thanks to the institutions that provided technical support for the development of this study.

\section{FINANCIAL SUPPORT}

National Health Fund, Ministry of Health. Dr. Deborah C. Malta received partial support from National Council for Scientific and Technological Development.

\section{AUTHORS' CONTRIBUTION}

EGR: Conception and design of the study, Acquisition of data, Analysis and interpretation of data, Drafting the article, Final approval of the version to be submitted; PCP: Conception and design of the study, Acquisition of data, Drafting the article, Analysis and interpretation of data, Final approval of the version to be submitted; BRN: Conception and design of the study, Final approval of the version to be submitted; JPPC: Conception and design of the study, Drafting the article, Final approval of the version to be submitted; RAT: Conception and design of the study, Acquisition of data, Analysis and interpretation of data, Final approval of the version to be submitted; JSN: Conception and design of the study, Acquisition of data, Final approval of the version to be submitted; TBF: Conception and design of the study, Final approval of the version to be submitted; LCCB: Conception and design of the study, Acquisition of data, Analysis and interpretation of data, Drafting the article, Final approval of the version to be submitted; DCM: Conception and design of the study, Acquisition of data, Analysis and interpretation of data, Drafting the article, Final approval of the version to be submitted.

\section{CONFLICT OF INTEREST}

The authors have no conflicts of interest to declare regarding this manuscript.

\section{ORCID}

Edmar Geraldo Ribeiro: 0000-0002-7201-9566

Pedro Cisalpino Pinheiro: 0000-0002-6954-1708

Bruno Ramos Nascimento: 0000-0002-5586-774X

João Pedro Pereira Cacique: 0000-0002-6687-6035

Renato Azeredo Teixeira: 0000-0002-1259-6812

Jamil de Souza Nascimento: 0000-0003-0764-4207

Tulio Batista Franco: 0000-0001-7372-5262

Luisa Campos Caldeira Brant: 0000-0002-7317-1367

Deborah Carvalho Malta: 0000-0002-8214-5734

\section{REFERENCES}

1. Cardiovascular Diseases Geneva, Switzerland: Wold Health Organization [Internet]; 2020. [updated 2020 July 10; cited 2020 July 5] Available from: https://www.who.int/health-topics/cardiovasculardiseases - tab $=$ tab_1.
2. Oliveira GMM, Brant LCC, Polanczyk CA, Biolo A, Nascimento BR, Malta DC, et al. Cardiovascular Statistics - Brazil 2020. Arq Bras Cardiol. 2020;115(3):308-439. Available from: https://doi.org/10.36660/ abc. 20200812

3. Ribeiro AL, Duncan BB, Brant LC, Lotufo PA, Mill JG, Barreto SM. Cardiovascular Health in Brazil: Trends and Perspectives. Circulation. 2016;133(4):422-33. Available from: https://doi 10.1161/ circulationaha.114.008727

4. Ministério da Saúde (MS). Indicadores e Dados Básicos de Saúde Brazil, 2020 [Internet]. Ministério da Saúde do Brazil. 2020 [cited July 10, 2020.]. Available from: https://www.gov.br/saude/pt-br.

5. De Filippo O, D'Ascenzo F, Angelini F, Bocchino PP, Conrotto F, Saglietto A, et al. Reduced Rate of Hospital Admissions for ACS during Covid-19 Outbreak in Northern Italy. N Engl J Med. 2020;383(1):88-9. Available from: https://doi: 10.1056/nejmc2009166

6. Normando PG, Araujo Filho JA, Fonseca GA, Rodrigues REF, Oliveira VA, Hajjar LA, Almeida ALC, et al. Redução na hospitalizaçao e aumento na mortalidade por doenças cardiovasculares durante a pandemia da COVID-19 no Brasil. Arq. Bras. Cardiol. 2021; 116(3):37180. Available from: https://doi.org/10.36660/abc.20200821

7. Maselli-Schoueri JH, de Carvalho LEW, Rezende LFM, Fonseca FLA, Ferrari G, Adami F. Hospital Admissions Associated With Noncommunicable Diseases During the COVID-19 Outbreak in Brazil. JAMA Netw Open. 2021;4(3):e210799. Available from: doi:10.1001/jamanetworkopen.2021.0799

8. Metzler B, Siostrzonek P, Binder RK, Bauer A, Reinstadler SJ. Decline of acute coronary syndrome admissions in Austria since the outbreak of COVID-19: the pandemic response causes cardiac collateral damage. Eur Heart J. 2020;41(19):1852-3. Available from: https://doi.org/10.1093/ eurheartj/ehaa314

9. Nishiga M, Wang DW, Han Y, Lewis DB, Wu JC. COVID-19 and cardiovascular disease: from basic mechanisms to clinical perspectives. Nat Rev Cardiol. 2020;17(9):543-58. Available from: https://doi: 10.1038/ s41569-020-0413-9

10. Hyndman RJ, Athanasopoulos G. Forecasting: principles and practice [Internet]. Melbourne, Australia: OTexts; 2020. Available from: https:// otexts.com/fpp2/

11. Decreto Municipal $n^{\circ} 17.298$, de 17 de março de 2020. Dispõe sobre medidas temporárias de prevenção ao contágio e de enfrentamento e contingenciamento, no âmbito do Poder Executivo, da epidemia de doença infecciosa viral respiratória causada pelo agente Coronavírus - COVID-19. . In: Horizonte SMdSdB, editor. 1 ed. Belo Horizonte - MG, Brazil. Em: Diário Oficial do Município. Belo Horizonte; 2020, n.5976, Seção Extra.: Prefeitura Municipal de Belo Horizonte; 2020. [updated 2020 Mar 17 cited 2020 Nov 10]. Available from: http://portal6.pbh.gov.br/dom/iniciaEdicao.do?method=DetalheArtigo\&pk= 1226966\#: :text=DECRETO \%20N\%C2\%BA\%2017.298\%2C\%20DE\%20 17,agente $\% 20$ Coronav $\%$ C3\%ADrus\%20\%E2\%80\%93\%20COVID $\% 2$ D 19 .

12. R Core Team (2020). R: A language and environment for statistical computing. R Foundation for Statistical Computing, Vienna, Austria. URL https://www.R-project.org/.

13. Rob Hyndman (2018). fpp2: Data for "Forecasting: Principles and Practice" (2nd Edition). R package version 2.3. https://CRAN.R-project. org/package $=$ fpp 2

14. De Rosa S, Spaccarotella C, Basso C, Calabro MP, Curcio A, Filardi PP, et al. Reduction of hospitalizations for myocardial infarction in Italy in the COVID-19 era. Eur Heart J. 2020 07;41(22):2083-8.

15. Oseran AS, Nash D, Kim C, Moisuk S, Lai PY, Pyhtila J, Sequist TD, Wasfy JH. Changes in hospital admissions for urgent conditions during COVID-19 pandemic. Am J Manag Care. 2020 Aug;26(8):327-328. doi: 10.37765/ajmc.2020.43837. 
16. Tam CF, Cheung KS, Lam S, Wong A, Yung A, Sze M, Lam YM, Chan C, Tsang TC, Tsui M, Tse HF, Siu CW. Impact of Coronavirus Disease 2019 (COVID-19) Outbreak on ST-Segment-Elevation Myocardial Infarction Care in Hong Kong, China. Circ Cardiovasc Qual Outcomes. 2020 Apr;13(4):e006631. doi: 10.1161/CIRCOUTCOMES.120.006631.

17. Solomon MD, McNulty EJ, Rana JS, Leong TK, Lee C, Sung SH, et al. The Covid-19 Pandemic and the Incidence of Acute Myocardial Infarction. N Engl J Med. 2020;383(7):691-3. Available from: https:// doi: $10.1056 /$ nejmc2015630

18. Wang X, Ouyang M, Carcel C, Chen C, Sun L, Yang J, et al. Impact of COVID-2019 on stroke services in China: survey from the Chinese Stroke Association. Stroke Vasc Neurol. 2020.

19. Wang X, Ouyang M, Carcel C, Chen C, Sun L, Yang J, et al. Impact of COVID-2019 on stroke services in China: survey from the Chinese Stroke Association. Stroke Vasc Neurol. 2020. Available from: http:// dx.doi.org/10.1136/svn-2020-000514

20. Noronha K, Guedes GR, Turra CM, Andrade MV, Botega L, Nogueira D, et al. The COVID-19 pandemic in Brazil: analysis of supply and demand of hospital and ICU beds and mechanical ventilators under different scenarios. Cad Saude Publica. 2020;36(6):e00115320. Available from: https://doi.org/10.1590/0102-311x00115320

21. Malta DC, Gomes CS, Silva AG, Cardoso LSM, Barros MBA, Lima MG, Souza Júnior PRB, Szwarcwald CL. Uso dos serviços de saúde e adesão ao distanciamento social por adultos com doenças crônicas na pandemia de COVID-19. Ciencias de Saude Coletiva. 2020 [internet] (2021/Mar) [Cited in 06/23/2021]. Available from: http://www. cienciaesaudecoletiva.com.br/artigos/uso-dos-servicos-de-saude-eadesao-ao-distanciamento-social-por-adultos-com-doencas-cronicasna-pandemia-de-covid19-brasil-2020/18004?id=18004\&id=18004

22. Malta DC, Szwarcwald CL, Barros MBA, Gomes CS, Machado IE, Souza Junior PRB, et al. The COVID-19 Pandemic and changes in adult Brazilian lifestyles: a cross-sectional study, 2020. Epidemiol Serv Saude. 2020;29(4):e2020407. Available from: https://doi.org/10.1590/ s1679-49742020000400026.

23. Kluge HHP, Wickramasinghe K, Rippin HL, Mendes R, Peters DH, Kontsevaya A, et al. Prevention and control of non-communicable diseases in the COVID-19 response. Lancet. 2020;395(10238):1678-80. Available from: https://doi.org/10.1016/S0140-6736(20)31067-9.

24. Banerjee A, Pasea L, Harris S, Gonzalez-Izquierdo A, Torralbo A, Shallcross L, et al. Estimating excess 1-year mortality associated with the COVID-19 pandemic according to underlying conditions and age: a population-based cohort study. Lancet. 2020;395(10238):1715-25. Available from: https://doi.org/10.1016/S0140-6736(20)30854-0.
25. Giattino C, Ritchie H, Roser M, Ortiz-Opina E, Hasell J. Excess mortality during the Coronavirus pandemic (COVID-19): Our World in Data; 2020 [updated 2020 Oct 1 cited 2020 Nov 10]. Available from: https:/ourworldindata.org/excess-mortality-covid.

26. Leon DA, Shkolnikov VM, Smeeth L, Magnus P, Pechholdova M, Jarvis CI. COVID-19: a need for real-time monitoring of weekly excess deaths. Lancet. 2020;395(10234):e81. Available from: https://doi.org/10.1016/ S0140-6736(20)30933-8.

27. Woolf SH, Chapman DA, Sabo RT, Weinberger DM, Hill L. Excess Deaths From COVID-19 and Other Causes, March-April 2020. JAMA. 2020;324(5):510-3. Available from: https://doi:10.1001/jama.2020.11787.

28. Science Daily. Study: 35 percent of excess deaths in pandemic's early months tied to causes other than COVID-19. 2020. Available from: https://www.sciencedaily.com/releases/2020/07/200701125506.htm

29. Baldi E, Sechi GM, Mare C, Canevari F, Brancaglione A, Primi R, et al. Out-of-Hospital Cardiac Arrest during the Covid-19 Outbreak in Italy. N Engl J Med. 2020;383(5):496-8. Available from: https://doi: 10.1056/ nejmc2010418

30. Brant LCC, Nascimento BR, Teixeira RA, Lopes M, Malta DC, Oliveira GMM, et al. Excess of cardiovascular deaths during the COVID-19 pandemic in Brazilian capital cities. Heart. 2020;106(24):1898-905. Available from: http://dx.doi.org/10.1136/heartjnl-2020-317663

31. Malta DC, Gomes CS, Souza Junior PRB, Szwarcwald CL, Barros MBA; Machado IE, et al. Factors associated with increased cigarette consumption in the Brazilian population during the COVID-19 pandemic. Cadernos de Saude Publica. 2021; 37:e00252220. Available from: doi: 10.1590/0102-311X00252220.

32. Werneck A, Silva D, Malta DC, Gomes CS Souza-Junior PRB, Azevedo L, Szwarcwald CL. Associations of sedentary behaviours and incidence of unhealthy diet during the COVID-19 quarantine in Brazil. Public Health Nutrition. 2021; 24(3): 422-426. Available from: doi: 10.1017/ S1368980020004188.

33. Informe de la evaluación rápida de la prestación de servicios para enfermedades no transmisibles durante la pandemia de COVID-19 en las Américas: Organização Pan-Americana de Saúde. 2020 [cited 2020 Nov 10]. Available from: https://iris.paho.org/handle/10665.2/52283.

34. Einstein AJ, Shaw LJ, Williams MC, Better N, Vitola J. Impact of Covid-19 on Heart Disease Diagnosis: Findings from 108 Countries. New England Journal of Medicine. 2020. [cited 2020 Nov 10]. Available from: https://www.nejm.org/ 